\title{
Role of a non-ionic surfactant in direct electron transfer-type bioelectrocatalysis by fructose dehydrogenase
}

\section{AUTHOR(S):}

Kawai, Shota; Yakushi, Toshiharu; Matsushita, Kazunobu; Kitazumi, Yuki; Shirai, Osamu; Kano, Kenji

\section{CITATION:}

Kawai, Shota ... [et al]. Role of a non-ionic surfactant in direct electron transfer-type bioelectrocatalysis by fructose dehydrogenase. Electrochimica Acta 2015, 152: 19-24

\section{ISSUE DATE:}

2015-01-10

URL:

http://hdl.handle.net/2433/192482

\section{RIGHT:}

(C) 2014 Elsevier Ltd.; This is not the published version. Please cite only the published version.; この論文は出版社版でありません。引用の際に は出版社版をご確認ご利用ください。 


\title{
Role of a non-ionic surfactant in direct electron transfer-type bioelectrocatalysis by fructose dehydrogenase
}

Shota Kawai ${ }^{\text {a }}$, Toshiharu Yakushi ${ }^{\text {b }}$, Kazunobu Matsushita ${ }^{\text {b }}$, Yuki Kitazumi ${ }^{\text {a }}$, Osamu Shirai ${ }^{\text {a }}$, and Kenji Kano ${ }^{\mathrm{a}, *}$

a Division of Applied Life Sciences, Graduate School of Agriculture, Kyoto University, Sakyo, Kyoto 606-8502, Japan

b Department of Biological Chemistry, Faculty of Agriculture, Yamaguchi University, Yamaguchi 753-8515, Japan

\begin{abstract}
A heterotrimeric membrane-bound fructose dehydrogenase (FDH) from Gluconobacter japonicus NBRC3260 contains FAD in subunit I and three heme C moieties in subunit II as the redox centers, and is one of the direct electron transfer (DET)-type redox enzymes. FDH-catalyzed current density of fructose oxidation at hydrophilic mercaptoethanol (MEtOH)-modified Au electrode is much larger than that at hydrophobic mercaptoethane (MEtn)-modified Au electrode. Addition of a non-ionic surfactant Triton ${ }^{\circledR}$ X-100 (1\%) completely quenches the catalytic current at the MEtnmodified Au electrode, while only small competitive effect is observed at the MEtOHmodified Au electrode. Quartz crystal microbalance measurements support the adsorption of FDH and Triton ${ }^{\circledR}$ X-100 on both of the modified electrodes. We propose a model to explain the phenomenon as follows. The surfactant forms a monolayer on the
\end{abstract}


hydrophobic MEtn-modified electrode with strong hydrophobic interaction, and FDH adsorbs on the surface of the surfactant monolayer. The monolayer inhibits the electron transfer from FDH to the electrode. On the other hand, the surfactant forms a bilayer on the hydrophilic MEtOH-modified electrode. The interaction between the surfactant bilayer and the hydrophilic electrode is relatively weak so that FDH replaces the surfactant and is embedded in the bilayer to communicate electrochemically with the hydrophilic electrode.

* Correspondence author. Tel: +81-75-753-6392, Fax: +81-75-753-6456, E-mail address: kano.kenji.5z@kyoto-u.ac.jp

\section{ARTICLE INFO}

Article history:

Received 9, September 2014

Keywords:

fructose dehydrogenase

self-assembled monolayer

surfactant layer

bioelectrocatalysis

direct electron transfer 


\section{Introduction}

Redox enzymes catalyze the electron transfer from the first substrate to the second substrate, and are involved in many vital processes including glycolysis process, tricarboxylic cycle, respiratory chain, and photosynthetic process [1,2]. Enzymes have the substrate specificity and recognize the intrinsic substrate in vivo. However, the substrate specificity for one of the two substrates is not so high for almost all redox enzymes. Therefore, the substrate may be replaced with artificial electron acceptor (or donor) in vitro, and the redox enzyme reactions can be combined with electrode reaction, when once the artificial electron acceptor (or donor) is reoxidized (or rereduced) at electrodes [3-5]. Furthermore, a limited number of enzymes can directly transfer electron to (or from) electrode [6-14]. The former and the latter are called mediated (MET) and direct electron transfer (DET)-type bioelectrocatalysis reactions, respectively. Both reactions are utilized to construct bioelectrochemical devices, such as biofuel cells and biosensors [5,7,15-17]. MET-type bio-devices might be superior in part to DET-type ones in the performance, since most of enzymes show rather low DET-type catalytic activity. However, DET-type bioelectrocatalysis reaction attracts great attention, because it avoids several problems concerning mediator [15-18]. It has been proposed that the following two characteristics are essential to realize DET-type bioelectrocatalysis [19]. One is that the enzyme has more than two redox centers. The second is that one of the redox centers is located near the enzyme surface to act as a built-in mediator for the fast electron transfer between the enzyme and electrode. There must exit another factors governing DET reaction. However, it is extremely difficult to find novel common features among DET-type enzymes. 
Multi-copper oxidases, such as laccase [8], copper efflux oxidase (CueO) [10] and bilirubin oxidase [20], are reported to act as DET-type enzymes for oxygen reduction. These enzymes commonly have a type 1 copper center and a type 2-3 copper cluster. On the other hand, DET-type enzymes for substrate oxidation have various cofactors, such as flavins, quinones, hemes and iron-sulfur clusters. We have focused on membrane-bound enzymes as a model group of DET-type enzymes for anodes, since a variety of membrane-bound enzymes including hydrogenase [11,12], gluconate dehydrogenase [13], and alcohol dehydrogenase [14] show high DET-type bioelectrocatalytic activity.

D-Fructose dehydrogenase (FDH; EC 1.1.99.11) from Gluconobacter japonicus NBRC3260 is a heterotrimeric membrane-bound enzyme. We have succeeded in constructing an overexpression system of FDH [21]. Subunits I and II have covalently bound flavin adenine dinucleotide (FAD) and three heme C moieties, respectively, while the function of subunit III is not clear at the present moment $[21,22]$. FDH shows strict substrate specificity to D-fructose and is used in diagnosis and food analysis [23, 24]. FDH is one of the redox enzymes capable of DET-type bioelectrocatalysis [25], and gives very large current density of DET-type fructose oxidation at a variety of electrodes [20,26-28]. The FAD is the catalytic site to accept electrons from the substrate, and the electrons are transferred to electrodes through the hemes C [29]. Subunit II is essential in the fast electron transfer from the solubilized FDH to electrode as well as ubiquinone derivatives [29]. For further discussion on the electron transfer pathway, some structural information will be required, but no information is available on the crystal structure of FDH at the present moment.

On the other hand, the effective DET reaction should require proper orientation 
such that the heme C moiety of FDH faces to electrode in a short distance to directly and quickly transfer electrons to electrode. Several surfactants are often used to avoid non-specific adsorption of proteins $[30,31]$ and then seem to more or less inhibit the DET-type bioelectrocatalysis due for example to preferred adsorption of the surfactant over enzymes. However, some non-ionic surfactants such as Triton ${ }^{\circledR} \mathrm{X}-100$ are required in solubilization of membrane-bound FDH from the membrane fraction. Subunit II containing three heme $\mathrm{C}$ moieties seems to be the membrane-anchoring moiety. The surfactant might adsorb on the membrane-anchoring region of the solubilized FDH. Considering the fact that FDH gives large catalytic current density in DET-type bioelectrocatalysis even in the presence of Triton ${ }^{\circledR} \mathrm{X}-100$ at several electrodes such as carbon electrodes [25], the surfactant might have an important role to adsorb FDH in a manner suitable for DET-type bioelectrocatalysis.

In this paper, we focus our attention on effects of Triton ${ }^{\circledR} \mathrm{X}-100$ on the DETtype bioelectrocatalysis caused by FDH. $\mathrm{Au}(111)$ is used as an electrode material, since the surface is sufficiently flat and the surface property is easily tuned by modification with several thiol molecules to fabricate self-assembled monolayer (SAM) [32]. We construct two kinds SAM-Au(111) electrodes with 2-mercaptoethanol (MEtOH) and mercaptoethane (MEtn) as hydrophilic and hydrophobic surface-containing electrodes, respectively. In addition, we focus on the change in the catalytic current density in the bioelectrocatalytic current measurements as well as the frequency shift in quartz micro balance (QCM) measurements as measures of the orientation, the distance, and the surface concentration of FDH on the electrodes. We propose a model of the adsorption of the surfactant and FDH to reasonably explain the experimental results. 


\section{Experimental}

\subsection{Materials}

MEtOH was purchased from Nacalai tesque (Japan). Other chemicals including MEtn and Triton ${ }^{\circledR}$ X-100 were from Wako Pure Chemical Industries (Japan). The expression and purification of FDH were carried out as described previously [21,22]. The fructose oxidation activity of solubilized FDH was measured spectrophotometrically with potassium ferricyanide and the ferric dupanol reagent, as described previously [22].

\subsection{Preparation of electrodes}

$\mathrm{Au}(111)$ electrodes were prepared on freshly cleaved mica surface by vapor deposition at a pressure less than $6.5 \times 10^{-4} \mathrm{~Pa}$. The temperature of a mica sheet was maintained at $580{ }^{\circ} \mathrm{C}$ during the deposition. Au-deposited mica sheets were subsequently annealed at $580{ }^{\circ} \mathrm{C}$ for $8 \mathrm{~h}$ and then quenched in ultrapure water.

SAM-modified Au(111) electrode was prepared by immersing the Au-coated mica substrates for at least $1 \mathrm{~h}$ in an ethanol solution containing $1 \mathrm{mM}$ of the corresponding thiol. Before measurements, SAM-modified Au(111) electrode was washed thoroughly with ethanol and ultrapure water in turn.

\subsection{Electrochemical measurements}

Cyclic voltammetry and chronoamperometry were carried out in McIlvaine buffer (pH 5.0) at $25^{\circ} \mathrm{C}$ with a BAS CV-50W electrochemical analyzer under anaerobic conditions. The working electrode was the Au(111) electrode, of which the projected 
surface area was $0.283 \mathrm{~cm}^{2}$. The reference and counter electrodes were a handmade Ag|AgCl|sat.KCl electrode and a Pt wire, respectively. All the potentials in this paper are referred to the reference electrode.

\subsection{QCM measurements with Au electrodes}

QCM measurements were performed on a Seiko EG\&G QCA917 QCM analyzer at the room temperature. 9-MHz At-cut quartz crystal plates were used (Seiko EG\&G Co., Ltd.), of which the projected surface area was $0.196 \mathrm{~cm}^{2}$.

\section{Results and discussion}

3.1. Catalytic currents at hydrophobic and hydrophilic electrodes in the absence of the surfactant

FDH was purified according to the literature [21,22]. The purified FDH solution contained $0.1 \%$ (w/w) Triton ${ }^{\circledR}$ X-100. Two $\mu \mathrm{L}$ of FDH solution $(40 \mu \mathrm{M})$ was added into $1 \mathrm{~mL}$ of the electrolytic test solution to adsorb FDH on the electrodes in this work, unless otherwise stated. The final concentration of Triton $X^{\circledR}-100(0.0002 \%)$ is sufficiently lower than the critical micelle concentration (CMC, $0.3 \mathrm{mM}(0.02 \%)$ [33]). Bioelectrocatalytic current measurements were performed in the McIlvaine buffer $(\mathrm{pH}$ 5.0) containing $200 \mathrm{mM}$ fructose. We used two types of thiols for constructing SAM on the $\mathrm{Au}(111)$ electrodes. The surfaces of MEtOH- and MEtn-modified electrodes are hydrophilic and hydrophobic, respectively.

Fig. 1, panel A shows cyclic voltammograms (CVs) of FDH-catalyzed fructose oxidation at MEtn- and MEtOH- SAM-modified and bare Au(111)electrodes. Fructose 
oxidation catalytic currents were observed at all of the electrodes examined, but the hydrophilic MEtOH-modifed Au electrode gave much larger current density than the hydrophobic MEtn-modified Au electrode. Furthermore, the MEtn-modified electrode showed low stability in the DET-type bioelectrocatalytic reaction (Fig. 1, panel B): multiple scanning in cyclic voltammetry caused a gradual decrease in the catalytic current. Similar phenomenon was observed at a hydrophobic Au(111) electrode modified with benzenthiol (data not shown). In contrast, the current response at the MEtOH-modified electrode was very stable during multiple scanning. Since clear frequency shift was not observed in QCM measurements during the potential scan at the FDH-adsorbed MEtn-modified Au electrode (data not shown), the decrease in the catalytic current would not be attributed to the desorption of FDH from the electrode surface. Some denaturation might occur at such hydrophobic electrode surface during the potential scan especially at positive potentials, as proposed for $\mathrm{CueO}$ which causes fatal denaturation in strong electric field on gold electrodes with positive surface charge density [34]. In addition, the MEtn-modified electrode provided strange characteristics: the catalytic current in the forward positive-going scan was smaller than that in the backward negative-going scan (Fig. 1, panel B). However, the reason is not clear.

\subsection{Effects of the surfactant adsorption on the DET-type catalytic current}

Our question here is whether FDH and the surfactant adsorb competitively or cooperatively on the electrodes. Therefore, we examined effects of the surfactant addition on the fructose oxidation current catalyzed by adsorbed FDH. After adding FDH in the test solution and stirring the solution for few seconds (during which FDH adsorbed on the electrodes), chronoamperometric monitoring of the catalytic current 
was performed at $500 \mathrm{mV}$. After the current reached a steady state under quiescent conditions, Triton ${ }^{\circledR} \mathrm{X}-100$ solution was added in the electrolysis solution (and the solution was stirred for few seconds) and the current response was monitored under quiescent conditions (surfactant post-addition experiments). The final concentration of the surfactant was set at $1 \%$, because it is identical with that set for the solubilization of FDH from the membrane fraction [21]. At this concentration of the surfactant, about $70 \%$ of FDH is solubilized from the membrane fraction by gentle stirring in MacIlvaine buffer (pH 6.0) for $1 \mathrm{~h}$ at $4{ }^{\circ} \mathrm{C}$ (data not shown). In addition, the specific activities of FDH in the presence and absence of $1 \%$ Triton $^{\circledR} \mathrm{X}-100$ were $160 \pm 20 \mathrm{U} \mathrm{mg}^{-1}$ and $180 \pm$ $12 \mathrm{U} \mathrm{mg}^{-1}$, respectively. Thus, we can conclude that there is no significant difference in the specific activity of FDH between in the presence and absence of $1 \%$ Triton ${ }^{\circledR} \mathrm{X}-100$ $(p<0.1$, Student's $t$ test; $n=6)$. Note here that the expression of "the absence of $1 \%$ Triton ${ }^{\circledR} \mathrm{X}-100$ ” in this paper does not mean the complete absence of the surfactant, but $0.0002 \%$ of the surfactant, as described in section 3.1 .

The chronoamperometric data are given in Fig. 2, panels A-C. At the hydrophobic MEtn-modified electrode, the catalytic current decreased down to almost zero immediately after the addition of the surfactant (panel A). The result suggests that FDH and the surfactant adsorb strongly competitively on the hydrophobic electrode surface. In contrast, at the hydrophilic MEtOH-modified electrode, the catalytic current retained about $80 \%$ of that before the addition of the 1\%-surfactant (panel B). Medium response was observed at the bare Au electrode (panel C).

The inset of Fig. 2, panel D shows CVs of FDH-catalyzed fructose oxidation at the MEtOH-modified electrode before and after the addition of the $1 \%$ surfactant. The surfactant addition caused only small decrease in the catalytic current, as in the case of 
the chronoamperometric measurements (Fig. 2, panel B), but the shape of the currentpotential curve remained unchanged, as evidenced by the normalized CVs depicted in panel D. By considering the property of the current-potential curve of DET-type bioelectrocatalysis in the presence of excess concentrations of substrate [35], the complete coincidence of the two normalized CVs before and after the addition of the surfactant indicates that the addition of the surfactant (1\%) causes only slight decrease in the surface concentration of the properly oriented FDH on the hydrophilic electrode surface, but both the electrode and enzymatic kinetics remained unchanged on the surfactant addition.

We also recorded CVs of FDH-catalyzed fructose oxidation at the SAMmodified electrodes in the presence of $1 \%$ Triton ${ }^{\circledR} \mathrm{X}-100$ before the addition of FDH (Fig. 3, surfactant pre-addition experiments). At the hydrophobic MEtn-modified Au electrode, no catalytic current was observed (panel A). The result also indicates that Triton $^{\circledR}$ X-100 adsorbs predominantly on the hydrophobic electrode to inhibit the DETtype bioelectrocatalysis.

In contrast, the addition of FDH caused the appearance of clear catalytic wave at the hydrophilic MEtOH-modified Au electrode even in the presence of the surfactant (1\%), as shown in panel B. The current density was almost identical with that observed in the surfactant post-addition experiments described before (dashed lined in the inset of Fig. 2, panel D). At the bare Au electrode, the catalytic wave was observed, but the current density was much smaller than that at the MEtOH-modified electrode. The effect of the pre-addition of the surfactant on the current was similar to that observed in the post-addition experiments. 


\subsection{QCM measurements and adsorption model}

The adsorption of the surfactant and FDH on the electrode was monitored on QCM. We first added 1\% Triton ${ }^{\circledR}$ X-100 into the test solution, and after the current reached a steady state under quiescent conditions, we succeedingly added FDH into the solution and the solution was stirred in few seconds. The time course of the resonance frequency ( $f$ ) is given in Fig. 4. At the MEtn-modified electrode, the $f$ value decreased immediately after the addition of Triton ${ }^{\circledR}$ X-100 at the position indicated by the solid arrow (curve A), indicating the strong adsorption of the surfactant on the hydrophobic surface most probably to form the monolayer. The succeeding addition of FDH at the position indicated by the dashed arrow also decreased the $f$ value under quiescent conditions, indicating the adsorption of FDH. By considering the complete inhibition of the DET-type bioelectrocatalysis by the surfactant addition and the strong attractive interaction between the surfactant and the hydrophobic surface, FDH most probably adsorbs on the monolayer of the surfactant, as illustrated in Fig. 5 (A).

It is reported that non-ionic surfactants form monolayer on hydrophobic surface at high concentrations of the surfactants $[36,37]$ in such a manner that the hydrophobic tail groups of the surfactant anchor to the hydrophobic surface and the hydrophilic head groups face the solution. The limiting value of the frequency shift $(\Delta f)$ on the addition of Triton ${ }^{\circledR} \mathrm{X}-100$ was about $-40 \mathrm{~Hz}$ at the MEtn-modified $\mathrm{Au}(111)$ electrode (Fig. 4, curve A), which corresponds to a mass change per unit area ( $\Delta m / A)$ of $2.0 \times 10^{2} \mathrm{ng} \mathrm{cm}^{-2}$ according to Sauerbrey equation [38].

$$
\Delta f=-\frac{2 f_{0}^{2} \Delta m}{A \sqrt{\mu_{\mathrm{q}} \rho_{\mathrm{q}}}}
$$

where $f_{0}$ is the fundamental resonance frequency $(9 \mathrm{MHz}), \mu_{\mathrm{q}}$ is the shear module $(2.947$ 
$\left.\times 10^{10} \mathrm{~kg} \mathrm{~m}^{-1} \mathrm{~s}^{-2}\right), \rho_{\mathrm{q}}$ is the density of the quartz $\left(2.648 \times 10^{3} \mathrm{~kg} \mathrm{~m}^{-3}\right)$, respectively. Assuming the monolayer formation of the surfactant and a molecular mass of $650 \mathrm{Da}$ for Triton ${ }^{\circledR}$ X-100 ( $n=10, n$ being the number of the polyethylene oxide group), rough evaluation of the area occupied by one molecule of Triton ${ }^{\circledR} \mathrm{X}-100$ yields 0.8 $(\mathrm{nm})^{2} /$ molecule. This value is reasonable as a projected area of Triton ${ }^{\circledR} \mathrm{X}-100$ viewed from the axis of the molecule. Therefore, the QCM data support the monolayer formation of Triton ${ }^{\circledR} \mathrm{X}-100$.

It can be expected that the monolayer formation of FDH causes a frequency shift $(\Delta f)$ of $-110 \mathrm{~Hz}$ by considering a molecular mass of $140 \mathrm{kDa}$ and an FDHoccupied area of $7(\mathrm{~nm})^{2} /$ molecule [26]. This expectation is verified by the QCM measurements of the adsorption of FDH on the MEtOH-modified or bare $\mathrm{Au}(111)$ electrode in the absence of the surfactant (Fig. S1). The $\Delta f$ value was about $50 \mathrm{~Hz}$ upon the adsorption of FDH on Triton ${ }^{\circledR}$ X-100-monolayer-adsorbed MEtn-modified electrode (Fig. 4, panel A). Therefore, the surface coverage of FDH adsorption layer on the Triton ${ }^{\circledR}$ X-100-monolayer may be calculated to be $0.4(=50 \mathrm{~Hz} / 110 \mathrm{~Hz})$. It seems to be difficult to transfer the electron from reduced FDH on the Triton ${ }^{\circledR} \mathrm{X}-100$-monolayer to the Au electrode through the Triton ${ }^{\circledR}$ X-100-monolayer (3-nm thickness) and the MEtnSAM (0.3-nm thickness), since long range electron transfer kinetics reduces exponentially as increasing the distance between electron donor and acceptor $[39,40]$. Actually, FDH falls silent in DET-type bioelectrocatalysis at the hydrophobic MEtn-Au electrode in the presence of Triton ${ }^{\circledR} \mathrm{X}-100$ (1\%).

Even at the MEtOH-modified Au electrode, the $f$ value decreased immediately after the addition of Triton ${ }^{\circledR} \mathrm{X}-100$ (Fig. 4, curve B). The limiting value of the frequency shift $(\Delta f)$ on the addition of Triton ${ }^{\circledR}$ X-100 was about $-100 \mathrm{~Hz}$. The result 
suggests the bilayer formation of Triton ${ }^{\circledR} \mathrm{X}-100$ on the hydrophilic surface. There are a number of studies on the behavior of non-ionic surfactants on silica/liquid interface $[41,42]$. It has been reported that Triton ${ }^{\circledR} \mathrm{X}-100$ forms bilayer at high concentrations on hydrophilic bare silica in such a manner that the adsorption of Triton ${ }^{\circledR} \mathrm{X}-100$ takes place through the ethoxy group on the silica and that the hydrophobic tail moiety is responsible for the bilayer formation.

On the succeeding addition of FDH into the solution, the frequency decreased gradually with the time, as shown by curve B of Fig. 4, indicating relatively slow adsorption of FDH on the Triton ${ }^{\circledR}$ X-100-bilayer-adsorbed MEtOH-modified Au electrode. Considering the fact that the FDH can communicate with the MEtOHmodified Au electrode, as evidenced by Fig. 2, panels B and D and Fig. 3, panel B, the situation can be ruled out that FDH adsorbs directly on the surface of the bilayer of Triton $^{\circledR}$ X-100. A more plausible model to be proposed here is that FDH inserts into the Triton $^{\circledR}$ X-100 bilayer and replaces parts of the bilayer, as illustrated in Fig. 5 (B). The interaction between the ethoxy group of Triton ${ }^{\circledR} \mathrm{X}-100$ and the hydroxyl group of MEtOH seems to be weak compared with that between FDH and MEtOH-SAM. It is reasonable to consider that the FDH embedded in the Triton ${ }^{\circledR} \mathrm{X}-100$ bilayer communicates with MEtOH-modified electrode in the presence of Triton ${ }^{\circledR}$ X-100. In addition, the situation in the proposed model is close to the native situation of FDH bound to the membrane, and seems to be convenient for FDH. This seems to be supported by the very large and stable response of FDH in DET-type bioelectrocatalysis at the hydrophilic MEtOH-modified Au electrode even in the presence of Triton ${ }^{\circledR} \mathrm{X}$ 100. The gradual decrease in the frequency on the addition of FDH (Fig. 4, panel B) seems to indicate the slow embedding process of FDH. 
About 20\% decrease in the catalytic current at the hydrophilic MEtOHmodified electrode on the addition of Triton ${ }^{\circledR}$ X-100 (Fig. 2, panel B and the inset in panel D) might be related with the solubilization process from the membrane fraction. Parts of the embedded FDH at very low concentration of the surfactant is solubilized by high concentrations of the surfactant. Since the solubilization ratio from the membrane fraction is about $70 \%$ for $1 \mathrm{~h}$ at $4{ }^{\circ} \mathrm{C}$ (see section 3.2), the surfactant bilayer might provide a stable situation for FDH compared with the phospholipid biomembrane. The interaction between FDH and the hydroxyl group of MEtOH might also contribute the stabilization of FDH in the bilayer-adsorbed MEtOH-modified Au electrode.

The bare Au electrode showed medium QCM response between the hydrophobic MEtn-modified electrode and hydrophilic MEtOH-modified electrode. Most probably, Triton ${ }^{\circledR}$ X-100 forms monolayer predominantly on bare Au electrode, but in only limited parts the bilayer is also constructed to embed FDH.

\section{Conclusion}

We have controlled the electrode surface hydrophobicity by using two types of SAMs to examine the effect of Triton ${ }^{\circledR}$ X-100 on DET-type bioelectrocatalysis of FDH. In the presence of the surfactant, the hydrophobic MEtn-modified electrode shows no response in the DET-type catalytic reaction of FDH in spite of the adsorption of FDH on the MEtn-modified electrode. We propose a model in which the surfactant monolayer is formed on the MEtn-modified electrode and FDH adsorbs on the surfactant monolayer. Under such conditions, the distance between the redox site of FDH and the electrode surface is too long to transfer the electron directly. In contrast, FDH is capable of DET- 
type communication with the hydrophilic MEtOH-modified electrode even in the presence of $1 \%$ Triton ${ }^{\circledR}$ X-100. The surfactant bilayer is formed on the MET-modified electrode. The interaction between the surfactant layer and the MEtOH-modified electrode is so weak that FDH can replace the bilayer in part and be embedded in the bilayer on the surface of the electrode. The proposed model is very important to consider the role of non-ionic surfactants in DET-type bioelectrocatalysis, especially, of membrane-bound redox enzymes.

\section{Acknowledgement}

This work was supported in part by a Grant-in-Aid for JSPS Fellows awarded to S. K. (\#26-1450).

\section{Appendix A: Supplementary information}

Supplementary data associated with this article can be found in the online version at http://

\section{References}

[1] P. N. Bartlett (Ed), Bioelectrochemistry, John Wiley \& Sons Ltd., West Sussex, 2008.

[2] G. W. Canters, E. Vijgenboom (Eds), Biological Electron Transfer Chains: Genetics, Composition and Mode of Operation, Kluwer Academic Publishers, Dordrecht, 1998.

[3] A. Heller, Miniature biofuel cells, Phys. Chem. Chem. Phys. 6 (2004) 209. 
[4] N. Mano, J. L. Fernandez, Y. Kim, W. Shin, A. J. Bard, A. Heller, Oxygen Is Electroreduced to Water on a “Wired” Enzyme Electrode at a Lesser Overpotential than on Platinum, J. Am. Chem. Soc. 125 (2003) 15290.

[5] C. Nieh, Y. Kitazumi, O. Shirai, M. Yamamoto, K. Kano, Potentiometric coulometry based on charge accumulation with a peroxidase/osmium polymerimmobilized electrode for sensitive determination of hydrogen peroxide, Electrochem. Commun. 33 (2013) 135.

[6] F. A. Armstrong, Recent developments in dynamic electrochemical studies of adsorbed enzymes and their active sites, Curr. Opin. Chem. Biol. 9 (2005) 110.

[7] L. Gorton, A. Lindgren, T. Larsson, F. D. Munteanu, T. Ruzgas, I. Gazaryan, Direct electron transfer between heme-containing enzymes and electrodes as basis for third generation biosensors, Anal. Chim. Acta. 400 (1999) 91.

[8] S. Shleev, J. Tkac, A. Christenson, T. Ruzgas, A. I.Yaropolov, J. W. Whittaker, L. Gorton, Direct electron transfer between copper-containing proteins and electrodes, Biosens. Bioelectron. 20 (2005) 2517.

[9] Y. Kamitaka, S. Tsujimura, N. Setoyama, T. Kajino, K. Kano, Fructose/dioxygen biofuel cell based on direct electron transfer-type bioelectrocatalysis, Phys. Chem. Chem. Phys. 9 (2007) 1793.

[10] Y. Miura, S. Tsujimura, Y. Kamitaka, S. Kurose, K. Kataoka, T. Sakurai, K. Kano, Bioelectrocatalytic Reduction of O2 Catalyzed by CueO from Escherichia coli Adsorbed on a Highly Oriented Pyrolytic Graphite Electrode, Chem. Lett. 36 (2007) 132.

[11] A. Ciaccafava, P. Infossi, M. Ilbert, M. Guiral, S. Lecomte, M. T. GiudiciOrticoni, E. Lojou, Electrochemistry, AFM, and PM-IRRA Spectroscopy of 
Immobilized Hydrogenase: Role of a Hydrophobic Helix in Enzyme Orientation for Efficient H2 Oxidation, Angew. Chem. 50 (2011) 1.

[12] H. R. Pershad, J. L. C. Duff, H. A. Heering, E. C. Duin, S. P. J. Albracht, F. A. Armstrong, Catalytic Electron Transport in Chromatium Vinosum [NiFe]Hydrogenase: Application of Voltammetry in Detecting Redox-Active Centers and Establishing That Hydrogen Oxidation Is Very Fast Even at Potentials Close to the Reversible H+/H2 Value, Biochemistry 38 (1999) 8992.

[13] S. Tsujimura, T. Abo, Y. Ano, K. Matsushita, K. Kano, Electrochemistry of DGluconate 2-Dehydrogenase from Gluconobacter frateurii on Indium Tin Oxide Electrode SurfaceChem. Lett. 36 (2007) 1164.

[14] T. Ikeda, D. Kobayashi, F. Matsushita, T. Sagara, K. Niki, Bioelectrocatalysis at electrodes coated with alcohol dehydrogenase, a quinohemoprotein with heme c serving as a built-in mediator, J. Electroanal. Chem. 361 (1993) 221.

[15] S. C. Barton, J. Gallaway, P. Atanassov, Enzymatic Biofuel Cells for Implantable and Microscale Devices, Chem. ReV. 104 (2004) 4867.

[16] J. A. Cracknell, K. A. Vincent, F. A. Armstrong, Enzymes as Working or Inspirational Electrocatalysts for Fuel Cells and Electrolysis, Chem. Rev. 108 (2008) 2439.

[17] K. So, S. Kawai, Y. Hamano, Y. Kitazumi, O. Shirai, M. Hibi, J. Ogawa, K. Kano, Improvement of a direct electron transfer-type fructose/dioxygen biofuel cell with a substratemodified biocathode, Phys. Chem. Chem. Phys. 16 (2014) 4823.

[18] J. T. Holland, C. Lau, S. Brozik, P. Atanassov, S. Banta, Engineering of Glucose Oxidase for Direct Electron Transfer via Site-Specific Gold Nanoparticle Conjugation, J. Am. Chem. Soc. 133 (2011) 19262. 
[19] T. Ikeda, Direct redox communication between enzymes and electrodes, in: F. W. Scheller, F. Schubert, J. Fedrowitz (Eds.), Frontiers in Biosensorics I, Birkhäuser Verlag Basel, Switzerland, 1997, p. 243.

[20] Y. Kamitaka, S. Tsujimura, T. Ikeda, K. Kano, Electrochemical Quartz Crystal Microbalance Study of Direct Bioelectrocatalytic Reduction of Bilirubin Oxidase, Electrochemistry 74 (2006) 642.

[21] S. Kawai, M. Tsutsumi, T. Yakushi, K. Kano, K. Matsushita, Heterologous Overexpression and Characterization of a Flavoprotein-Cytochrome c Complex Fructose Dehydrogenase of Gluconobacter japonicus NBRC3260, Appl. Environ. Microbiol. 79 (2013) 1654.

[22] M. Ameyama, E. Shinagawa, K. Matsushita, O. Adachi, D-Fructose Dehydrogenase of Gluconobacter industrius: Purification, Characterization, and Application to Enzymatic Microdetermination of D-Fructose, J. Bacteriol. 145 (1981) 814.

[23] R. Antiochia, L. Gorton, A new osmium-polymer modified screen-printed graphene electrode for fructose detection, Sens. Actuators B 195 (2014) 287.

[24] K. Nakashima, H. Takei, O. Adachi, E. Shinagawa, M. Ameyama, Determination of seminal fructose using D-fructose dehydrogenase, Clin. Chim. Acta. 151 (1985) 307.

[25] Y. Kamitaka, S. Tsujimura, K. Kano, High Current Density Bioelectrolysis of DFructose at Fructose Dehydrogenase-adsorbed and Ketjen Black-modified Electrodes without a Mediator, Chem. Lett. 36 (2007) 218. 
[26] M. Tominaga, C. Shirakihara, I. Taniguhi, Direct heterogeneous electron transfer reactions and molecular orientation of fructose dehydrogenase adsorbed onto pyrolytic graphite electrodes, J. Electroanal. Chem. 610 (2007) 1.

[27] K. Murata, M. Suzuki, K. Kajiya, N. Nakamura, H. Ohno, High performance bioanode based on direct electron transfer of fructose dehydrogenase at gold nanoparticle-modified electrodes, Electrochem. Commun. 11 (2009) 668.

[28] T. Miyake, S. Yoshino, T. Yamada, K. Hata, M. Nishizawa, Self-Regulating Enzyme-Nanotube Ensemble Films and Their Application as Flexible Electrodes for Biofuel Cells, J. Am. Chem. Soc. 133 (2011) 5129.

[29] S. Kawai, T. Yakushi, K. Matsushita, Y. Kitazumi, O. Shirai, K. Kano, The electron transfer pathway in direct electrochemical communication of fructose dehydrogenase with electrodes, Electrochem. Commun. 38 (2014) 28.

[30] R. Miller, V. B. Fainerman, R. Wüstneck, J. Krägel, D. V. Trukhin, Characterisation of the initial period of protein adsorption by dynamic surface tension measurements using different drop techniques, Colloids. Surf. A 131 (1998) 225.

[31] L. S. Roach, H. Song, R. F. Ismagilov, Controlling Nonspecific Protein Adsorption in a Plug-Based Microfluidic System by Controlling Interfacial Chemistry Using Fluorous-Phase Surfactants, Anal. Chem. 77 (2005) 785.

[32] H. Ron, S. Matlis, I. Rubinstein, Self-Assembled Monolayers on Oxidized Metals. 2. Gold Surface Oxidative Pretreatment, Monolayer Properties, and Depression Formation, Langmuir 14 (1998) 1116.

[33] M. N. Jones, Surfactants in membrane solubilisation, Int. J. Phytorem. 177 (1999) 137. 
[34] Y. Sugimoto, Y. Kitazumi, S. Tsujimura, O. Shirai, M. Yamamoto, K. Kano, Electrostaticinteractionbetweenanenzymeandelectrodesinthe electric doublelayerexaminedinaviewofdirectelectron transfer-typebioelectrocatalysis, Biosens. Bioelectron. 63 (2015) 138.

[35] S. Tsujimura, T. Nakagawa, K. Kano, T. Ikeda, Kinetic Study of Direct Bioelectrocatalysis of Dioxygen Reduction with Bilirubin Oxidase at Carbon Electrode, Electrochemistry 72 (2004) 437.

[36] F. Tiberg, Physical characterization of non-ionic surfactant layers adsorbed at hydrophilic and hydrophobic solid surfaces by time-resolved ellipsometry, J. Chem. Soc. Faraday Trans. 92 (1996) 531.

[37] L. M. Grant, T. Ederth, F. Tiberg, Influence of Surface Hydrophobicity on the Layer Properties of Adsorbed Nonionic Surfactants, Langmuir 16 (2000) 2285.

[38] G. Sauerbrey, Verwendung von Schwingquarzen zur Wägung diinner Schichten und zur Mikrowägung, Z. Phys. 155 (1959) 206.

[39] H. B. Gray, J. R. Winkler, Long-range electron transfer, Pro. Natl. Acad. Soc. 102 (2005) 3534.

[40] A. Ghindilis, P. Atanasov, E. Wilkins, Enzyme-Catalyzed Direct Electron Transfer: Fundamentals and Analytical Applications, Electroanalysis 9 (1997) 661.

[41] G. González, A. M. Travalloni-Louvisse, The Effect of Triton X-100 and Ethanol on the Wettability of Quartz, Langmuir 5 (1989) 26.

[42] D. M. Nevskaia, M. L. R. Cervantes, A. G. Ruíz, J. de D. López-González, Interaction of Triton X-100 on Silica : a Rela tionship between Surface Characteris tics and Adsorption Isotherms, J. Chem. Tech. Biotechnol. 63 (1995) 249. 


\section{Figure Captions}

Fig. 1. (A): CVs of fructose oxidation catalyzed by FDH adsorbed on (1, green line) MEtn-modified, (2, blue line) MEtOH-modified, and (3, red line) bare Au electrode in the presence of $200 \mathrm{mM}$ fructose.

(B): Multi-scan CVs at FDH-adsorbed MEtn-modified electrode (broken black line) in the absence and (1st cycle: green line, 2nd cycle: yellowish green line) presence of fructose (200 mM). All CVs were recorded at $\mathrm{pH} 5.0$ and $v=10 \mathrm{mV} \mathrm{s}^{-1}$.

Fig. 2. DET-type FDH-catalyzed current response in the presence of $200 \mathrm{mM}$ fructose. (A-C) Chronomperometric response on MEtn-modified (A), MEtOH-modified (B), and bare (C) $\mathrm{Au}(111)$ electrode at $500 \mathrm{mV} .1 \%$ Triton ${ }^{\circledR} \mathrm{X}-100$ was added to the electrolysis solution at the point indicated by the arrow.

(D): Relative current expression of CVs of FDH-catalyzed fructose oxidation at MEtOH-modified Au(111) electrode before (blue solid line) and after (pink dashed line) the addition of $1 \%$ Triton ${ }^{\circledR} \mathrm{X}-100$. The current is normalized against the value at 500 $\mathrm{mV}$. The inset shows the original CV data, in which the black solid line is the background CV.

Fig. 3. CVs of fructose oxidation catalyzed FDH adsorbed on (A) MEtn-modified, (B) MEtOH modified, and (C) bare $\mathrm{Au}(111)$ electrodes in the presence of $200 \mathrm{mM}$ fructose and $1 \%$ Triton ${ }^{\circledR} \mathrm{X}-100$. All CVs were performed at $\mathrm{pH} 5.0$ and $v=10 \mathrm{mV} \mathrm{s}^{-1}$. The background CVs (in the absence of fructose) are given by the broken curves.

Fig. 4. Frequency changes on the addition of $1 \%$ Triton $^{\circledR} \mathrm{X}-100$ (at the solid arrow) and 
FDH (at the dashed arrow) at (A, green line) MEtn-modified, (B, blue line) MEtOHmodified, and (C, red line) bare Au electrodes.

Fig. 5. The proposed scheme of the adsorption of FDH and Triton ${ }^{\circledR} \mathrm{X}-100$ at (A) hydrophobic and (B) hydrophilic electrodes. 

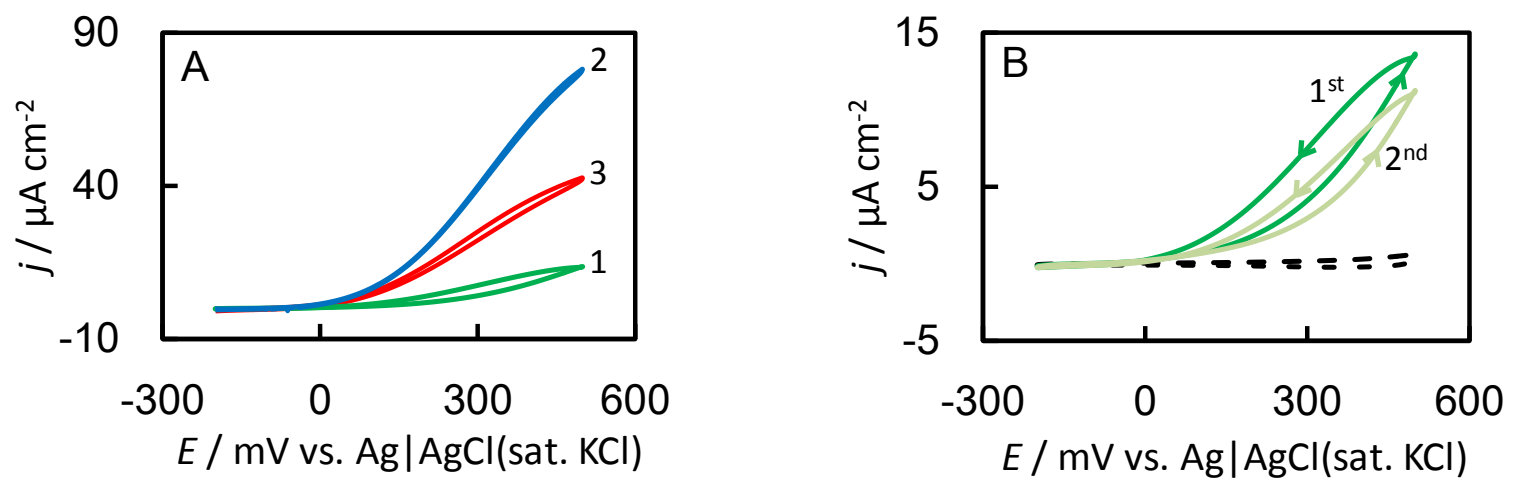

Fig. 1
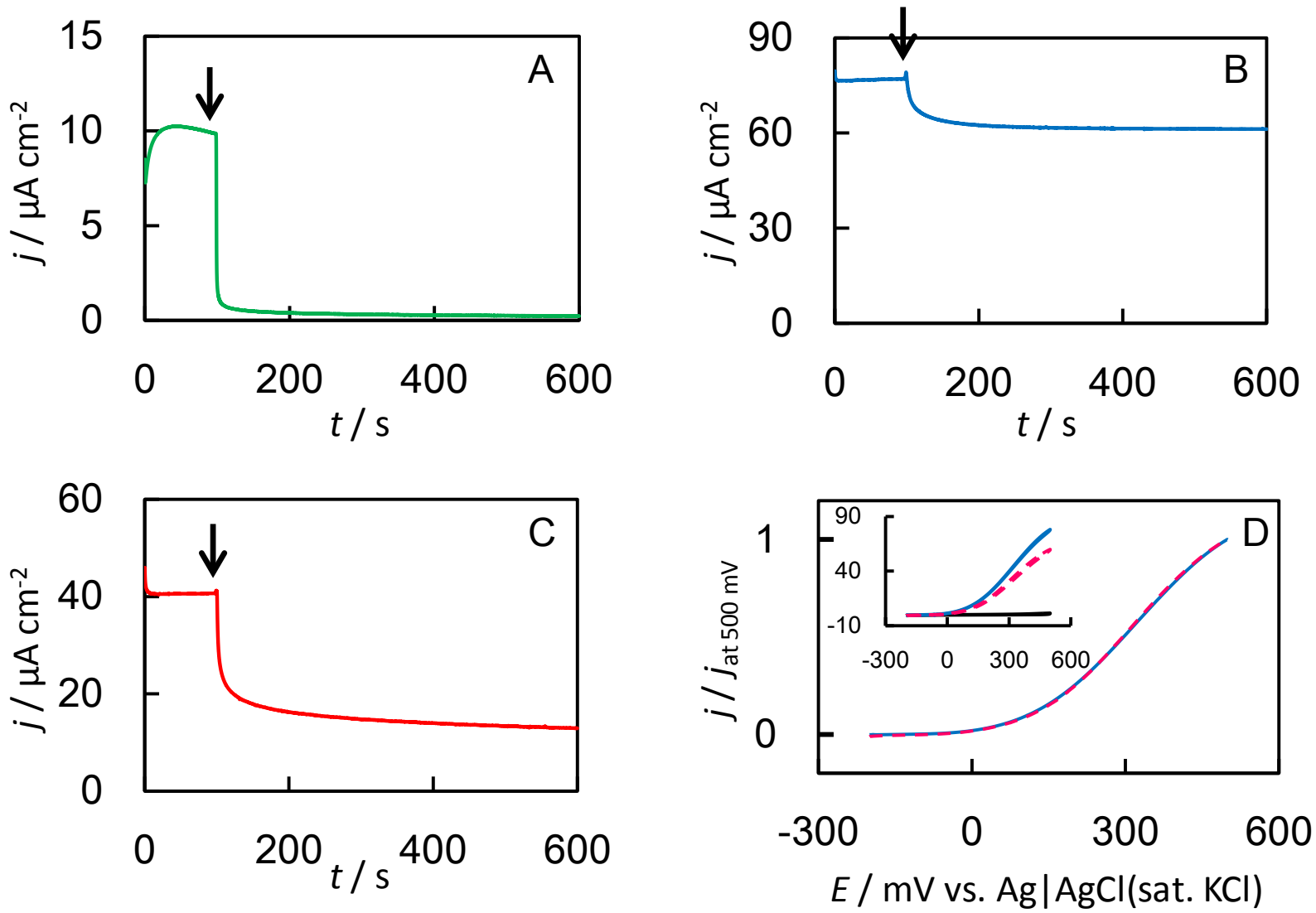

Fig.2 

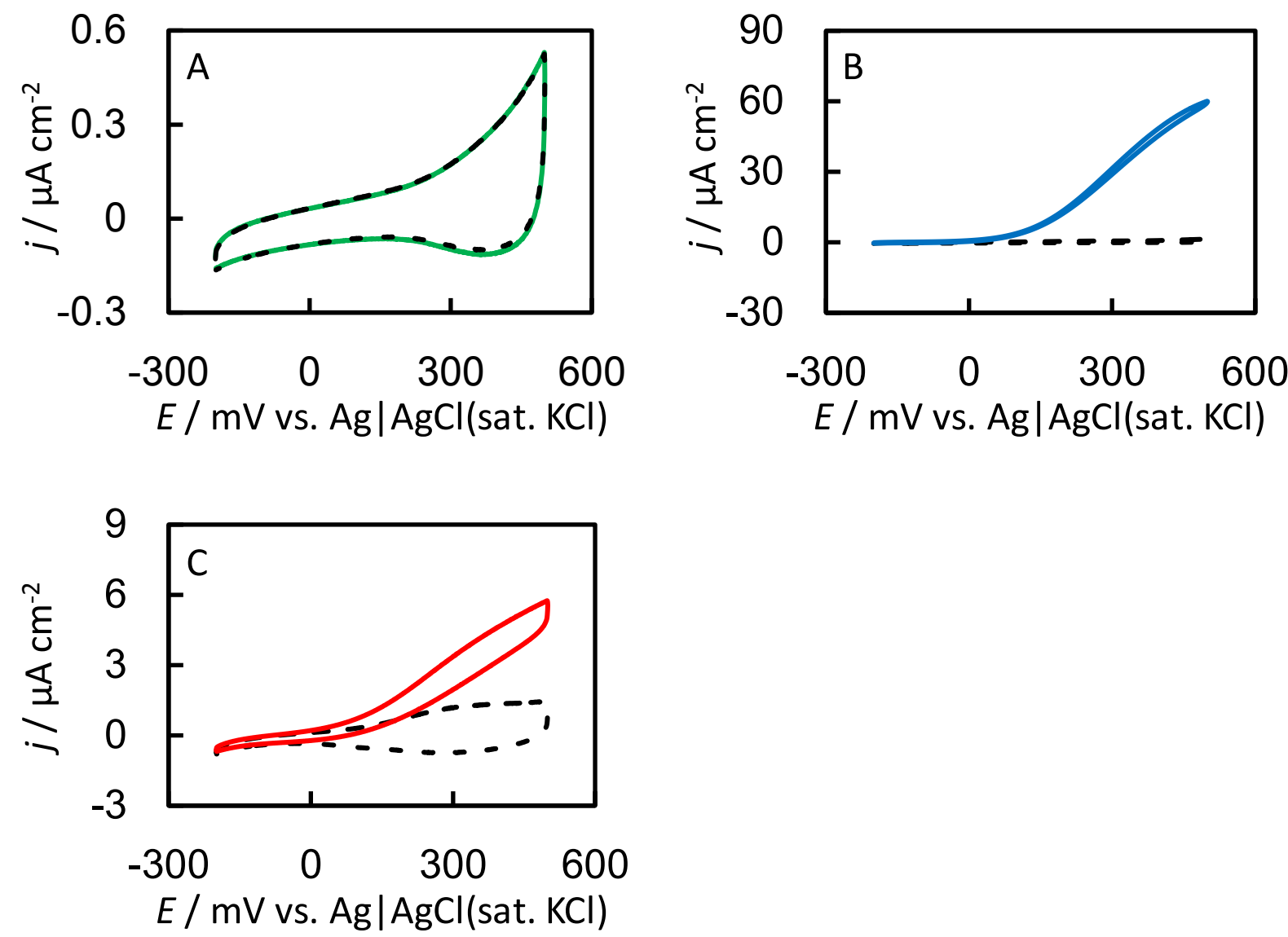

Fig. 3

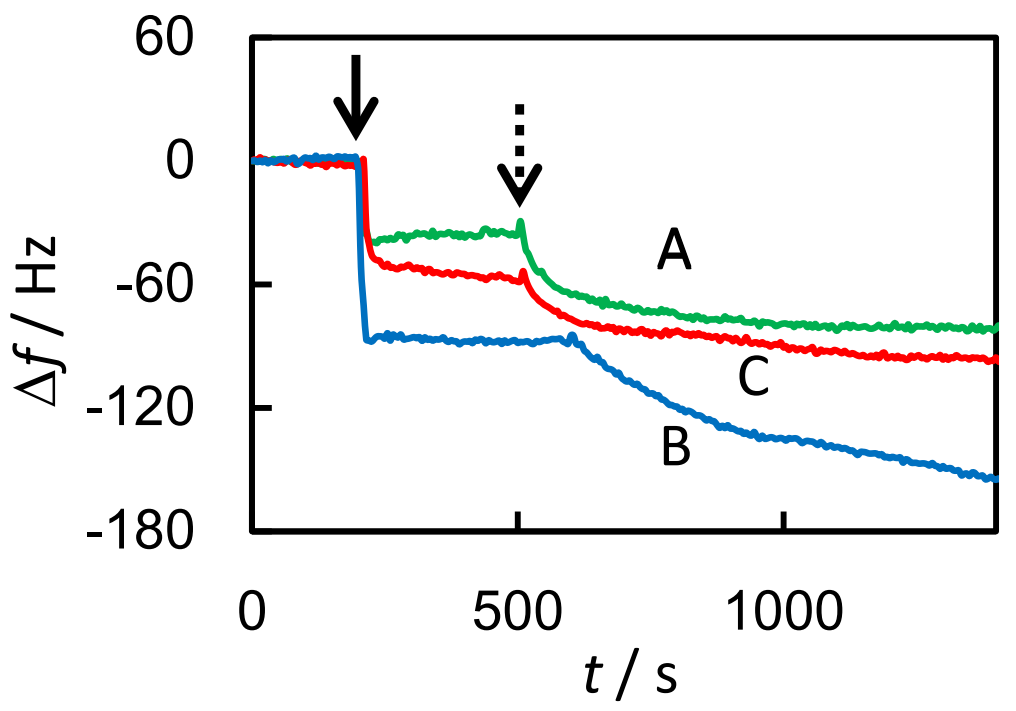

Fig. 4 

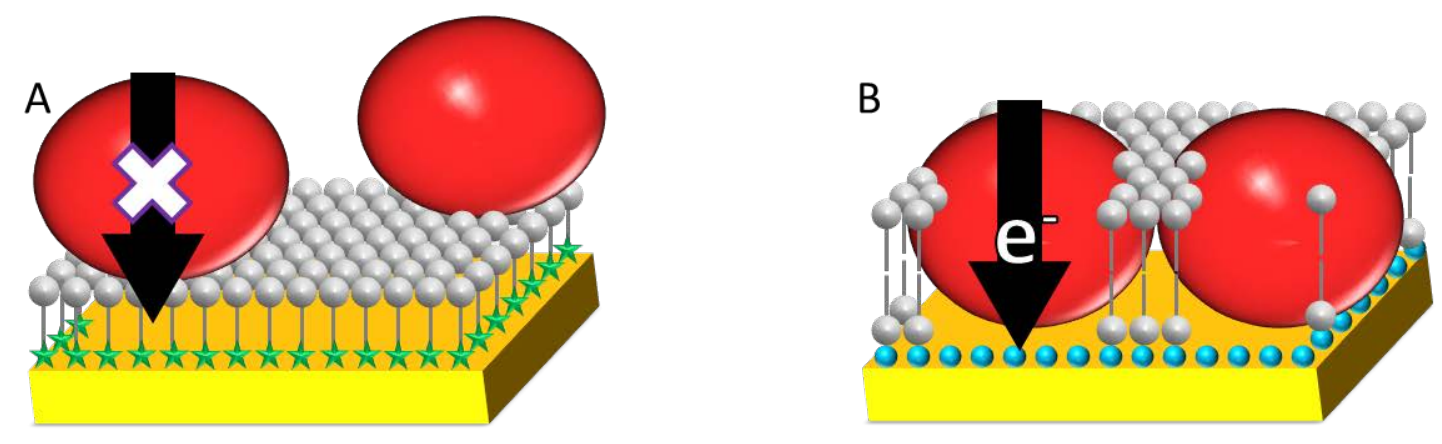

$\star$ : mercaptoethane

๑: mercaptoethanol
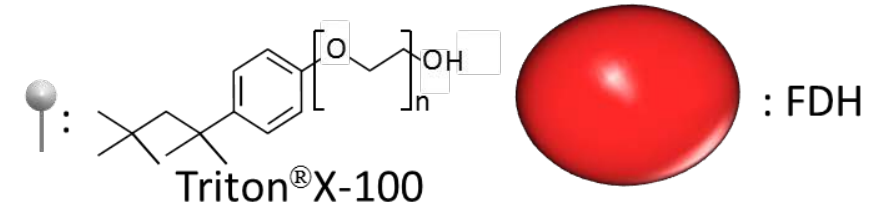

Fig. 5 


\section{Role of a non-ionic surfactant in direct electron transfer-type bioelectrocatalysis by fructose dehydrogenase}

Shota Kawai ${ }^{\text {a }}$, Toshiharu Yakushi ${ }^{\text {b }}$, Kazunobu Matsushita ${ }^{\text {b }}$, Yuki Kitazumi ${ }^{\text {a }}$, Osamu Shirai ${ }^{a}$, and Kenji Kano ${ }^{\text {a,* }}$

a Division of Applied Life Sciences, Graduate School of Agriculture, Kyoto University, Sakyo, Kyoto 606-8502, Japan

b Department of Biological Chemistry, Faculty of Agriculture, Yamaguchi University, Yamaguchi 753-8515, Japan

Supplementary information
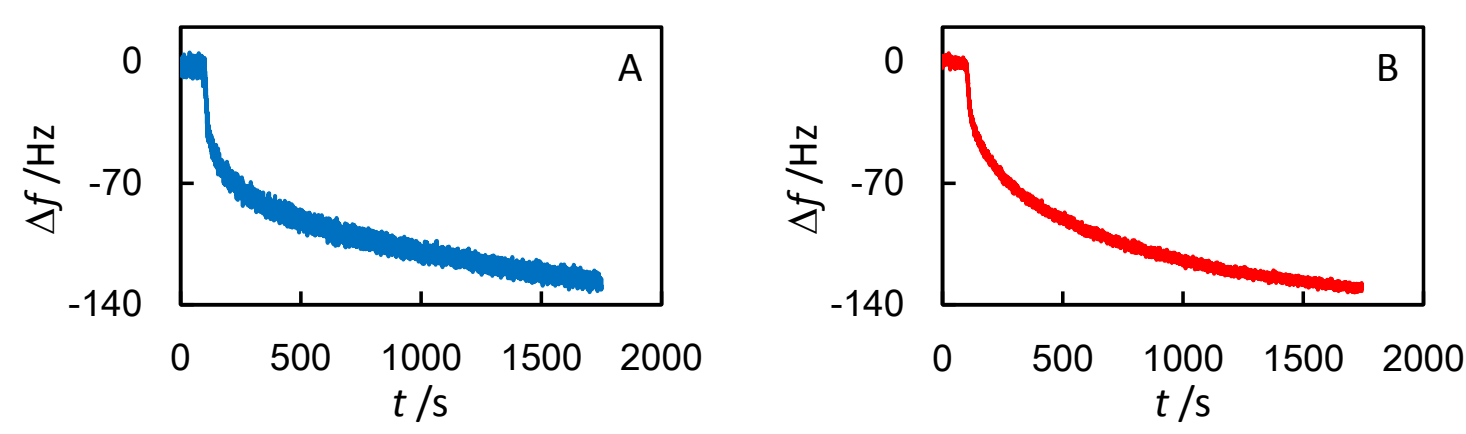

Fig. S1. Frequency changes on the adsorption of FDH in the absence of $1 \%$ Triton ${ }^{\circledR} \mathrm{X}$ 100 at (A) MEtOH-modified and (B) bare Au electrodes. 